Article

\title{
Preparation and Characterization of Core-Shell Structure Hard Carbon/Si-Carbon Composites with Multiple Shell Structures as Anode Materials for Lithium-Ion Batteries
}

\author{
Jong-Chan Kim, Kyung-Jin Kim and Sung-Man Lee * \\ Department of Materials Science \& Engineering, Kangwon National University, Gangwondaehakgil, \\ Gangwon-do, Chuncheon-si 24341, Korea; nadri2001@naver.com (J.-C.K.); secondragon@nate.com (K.-J.K.) \\ * Correspondence: smlee@kangwon.ac.kr; Tel.: +82-33-250-6266
}

\begin{abstract}
Novel core-shell structure hard carbon/Si-carbon composites are prepared, and their electrochemical performances as an anode material for lithium-ion batteries are reported. Three different types of shell coating are applied using Si-carbon, Si-carbon black-carbon and Si-carbon black-carbon/graphite nanosheets. It appears that the use of n-Si/carbon black/carbon composite particles in place of $\mathrm{n}-\mathrm{Si}$ for the shell coating is of great importance to achieve enhanced electrochemical performances from the core-shell composite samples, and additional wrapping with graphite nanosheets leads to a more stable cycle performance of the core-shell composites.
\end{abstract}

Keywords: core-shell composites; Li-ion battery; anode material; hard carbon; Si-carbon composites

check for updates

Citation: Kim, J.-C.; Kim, K.-J.; Lee, S.-M. Preparation and Characterization of Core-Shell Structure Hard Carbon/Si-Carbon Composites with Multiple Shell Structures as Anode Materials for Lithium-Ion Batteries. Energies 2021, 14, 2104. https://doi.org/10.3390/ en14082104

Received: 3 March 2021

Accepted: 7 April 2021

Published: 9 April 2021

Publisher's Note: MDPI stays neutral with regard to jurisdictional claims in published maps and institutional affiliations.

Copyright: (c) 2021 by the authors. Licensee MDPI, Basel, Switzerland. This article is an open access article distributed under the terms and conditions of the Creative Commons Attribution (CC BY) license (https:// creativecommons.org/licenses/by/ $4.0 /)$.

\section{Introduction}

Lithium-ion batteries (LIBs) are widely used in many applications but there is an increasing demand for higher energy and power density. These characteristics are mainly determined by which cathode and anode materials are used. Among various anode materials, silicon has been investigated as one of the most promising alternatives to conventional graphite anodes because of its high theoretical specific capacity (about $4200 \mathrm{mAh} / \mathrm{g}$ ) [1].

However, the practical application of $\mathrm{Si}$ as an anode material is currently impeded by its large volume change $(\sim 300 \%)$ during lithiation and delithiation, resulting in capacity fading and a limited lifecycle. Moreover, the rate capability of Si electrodes is limited by the low electronic conductivity of Si and low lithium diffusion rates in Si [2-4]. Great efforts have been devoted to achieving improved structural stability and electrical performance of Si based anodes [5-10]. Silicon-carbon composites using nanoscale Si have been recognized as a favorable approach to solve the abovementioned problems. Numerous studies have demonstrated that the drawbacks of $\mathrm{Si}$ as an anode material could be mitigated by reducing the size of the Si particle. The dispersion of nanoscale $\mathrm{Si}$ in a carbon matrix has been a favorable approach in synthesizing Si-based anode materials for LIBs because it improves the performance of $\mathrm{Si}$ through avoiding the direct contact with electrolytes [11,12]. On the one hand, the dispersion of nanosized Si particles in a carbon matrix is known to be challenging since these nanosized particles are prone to forming agglomerations [13,14]. On the other hand, it is anticipated that the problem in dispersion of nanosized Si particles will be overcome by synthesizing a Si-carbon black (CB) carbon composite [15].

Graphene (or graphite nanosheet) is regarded as a promising carbonaceous material for silicon-carbon composites due to its unique properties, in which graphene can provide an electrically conductive network and structural support for accommodating the mechanical stress, thus enhance the electrochemical performance of Si-based composites [16,17]. It also appears that the graphene could act as a protective barrier, inhibiting the Si particles from being directly exposed to the electrolyte [18].

To improve energy densities and simultaneously alleviate mechanical instabilities of electrodes, composite electrodes containing a small portion of Si have been increasingly 
researched $[19,20]$. However, little attention has been paid to an approach for improving their rate performance.

In this study, by combining several of the abovementioned aspects, a unique core-shell structure hard carbon/Si-carbon composites with multiple shell structures were synthesized to be applied as anode materials for LIBs. The concept was to improve the power density and energy efficiency by adopting a hard carbon with a high-rate capability as a core material and distributing Si nanoparticles in the shell layer. Thereby, it was expected that the utilization of active electrode materials would increase. In particular, we investigated the effect of the shell structure in the composite material on its electrochemical performance as an anode material for LIBs, in which we employed three types of shell structure: Si-carbon, Si-carbon black-carbon and Si-carbon black-carbon/graphite nanosheet. The resultant composite materials are denoted as Hard carbon/Si-carbon composite, Hard carbon/Si-carbon black-carbon composite and Hard carbon/Si-carbon black-carbon/graphite nano-sheet composite, respectively.

\section{Materials and Methods}

n-Si/Carbon black composite (SCB). Si nanoparticles (n-Si, D50 40 nm, Solirex, Inc., Daejeon-si, Korea) and carbon black (set to 60:40 in weight ratio, Thermo Fisher Scientific, Inc., Waltham, MA, USA) were dispersed in a polyacrylic acid (PAA), (Sigma-Aldrich, Inc., Darmstadt, Germany) water solution. The dispersion was spray-dried and heated at $1000{ }^{\circ} \mathrm{C}$ under an Ar atmosphere for the carbonization of PAA, followed by ball milling to produce SCB particles with an average particle size of $200 \mathrm{~nm}$. The discharge capacity of SCB was $2415 \mathrm{mAh} \mathrm{g}^{-1}$.

Hard carbon/Si-carbon composite (HSC). Hard carbon (D50 8 $\mu \mathrm{m}$, Aekyoung petrochemical Co., Ltd., Seoul, Korea) and n-Si were mixed with a tetrahydrofuran (THF) solution containing dissolved petroleum pitch, then it was dried in a vacuum at room temperature. The dried mixture was transferred into a homemade agglomerator to prepare the core-shell composite. The material was heated under an argon atmosphere up to $1000{ }^{\circ} \mathrm{C}$ at $10^{\circ} \mathrm{C} \mathrm{min}^{-1}$ and kept for $1 \mathrm{~h}$.

Hard carbon/Si-carbon black-carbon composite (HSBC). To prepare a HSBC, SCB was used instead of n-Si, and the core-shell production procedure was same as that in HSC.

Hard carbon/Si-carbon black-carbon/graphite nano-sheet composite (HSBGC). HSBGC was obtained by encapsulating HSBC particles with graphite nanosheets/carbon mixture. The encapsulating process was performed by mixing HSBC particles and graphite nanosheets (Samjungcng Co., Ltd., Gyeongsan-si, Korea) in a carbon precursor (e.g., pitch) dissolved solution and then dried. This was followed with applying a mechanical shear force using a homemade agglomerator.

The hierarchical structures of SCB and core-shell composites, HSC, HSBC and HSBGC, are illustrated in Schemes 1 and 2, respectively.

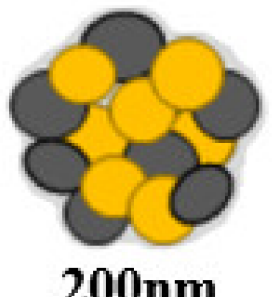

$200 \mathrm{~nm}$
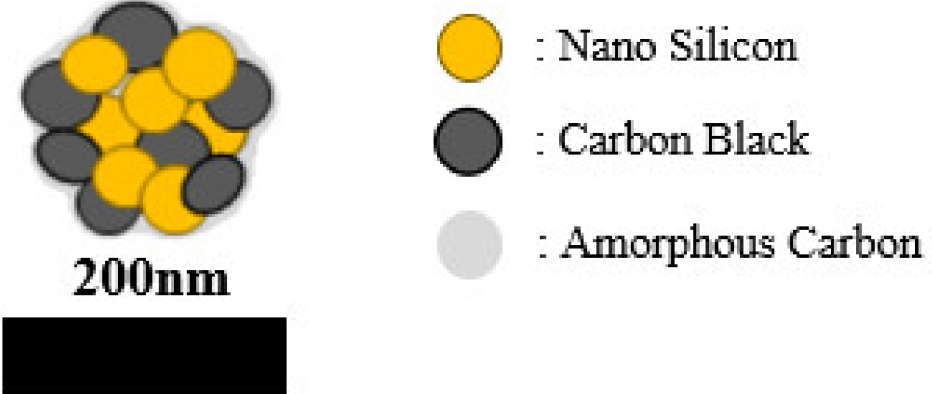

Scheme 1. The Schematic diagram of SCB. 
(a)

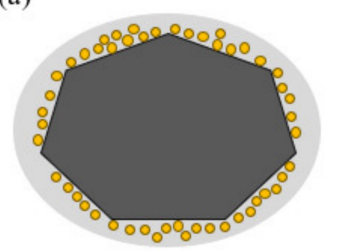

(b)

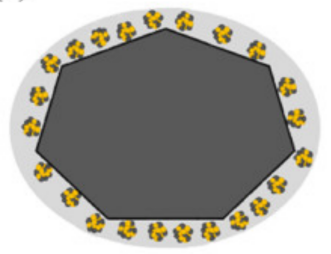

(c)

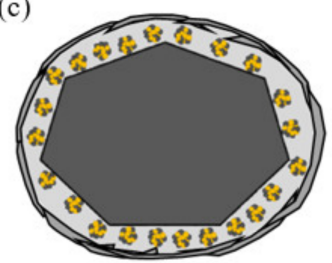

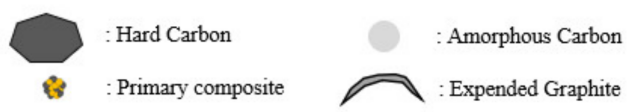

Scheme 2. The Schematic diagram of core/shell composite (a) HSC, (b) HSBC and (c) HSBGC.

\subsection{Characterization}

Scanning electron microscopy images were obtained by a field-emission scanning electron microscope (FE-SEM S-4300, HITACHI High-Tech Co., Ltd., Tokyo, Japan). The crystal structure was determined by $\mathrm{X}$-ray diffraction $(\mathrm{XRD})$ with $\mathrm{Cu} \mathrm{K} \alpha$ radiation. The size distribution of composite particles was determined by a Laser Particle Size Analyzer (Mastersizer 2000, Malvern Panalytical Ltd, Malvern, England). The structure of the composites was investigated with a transmission electron microscope (TEM, JEM-2100F, JEOL Ltd, Akishima, Tokyo) and high-resolution TEM (HRTEM).

\subsection{Electrochemical Measurements}

The electrochemical tests were carried out using a coin-type cell (CR2032, Wellcos Co., Ltd., Gunpo-si, Korea). The coin cells were assembled in an argon-filled glove box with lithium foil as the counter electrode and $1 \mathrm{M} \mathrm{LiPF}_{6}$ in ethylene carbonate (EC) diethyl carbonate (DEC) (1:1 by volume) as the electrolyte. The working electrodes were made by spreading an aqueous slurry containing $85 \mathrm{wt} \%$ active material, $5 \mathrm{wt} \%$ super $\mathrm{P}$ and $10 \mathrm{wt} \%$ binder (polyacrylic acid) onto a $\mathrm{Cu}$ foil, followed by drying at $180^{\circ} \mathrm{C}$ in a vacuum oven for $12 \mathrm{~h}$ and then pressing. The electrodes had an active material loading of ca. $5 \mathrm{mg} \mathrm{cm}^{-2}$. To measure the discharge capacity of SCB, the electrode was fabricated by using $60 \mathrm{wt} . \%$ active material, $20 \mathrm{wt} . \%$ super $\mathrm{P}$ and $20 \mathrm{wt} . \%$ binder (polyacrylic acid) with a low mass loading of ca. $1 \mathrm{mg} \mathrm{cm}^{-2}$.

An electrochemical evaluation was performed with the WBCS3000, WonATech. The cells were charged (lithiated) and discharged (delithiated) between 0.02 and $2.0 \mathrm{~V}$ at $30^{\circ} \mathrm{C}$. For the first formation cycle, the cells were charged in the constant current-constant voltage $(\mathrm{CC}-\mathrm{CV})$ mode and discharged at a constant current of $0.2 \mathrm{C}$. To evaluate the cycle performance, the cells were galvanostatically charged and discharged at a rate of $0.2 \mathrm{C}$. For the charge rate capability measurements, the electrodes were charged in the CC mode at different rates ranging from 0.2 to $5 \mathrm{C}$ and discharged at $0.2 \mathrm{C}$. Electrochemical impedance spectroscopy (EIS) measurements were performed in the discharged state at a frequency range of $1 \mathrm{MHz}$ to $10 \mathrm{mHz}$ with an amplitude of $5 \mathrm{mV}$.

\section{Results and Discussion}

Figure 1a-e show typical SEM images of the pristine n-Si, hard carbon and composite samples, HSC, HSBC and HSBGC, respectively. The hard carbon particles exhibit sharp-edged shapes, while the composite samples appear to be rounded as a result of the formation of the shell layer, as shown in Figure 1c-e. It should be noted here that SCB was used instead of n-Si to form the composite materials, HSBC and HSBGC. Figure 2 shows the TEM image and energy dispersive spectroscopy (EDS) spectra of the SCB particles. From the HRTEM image in Figure 2d, the Si nanoparticles are shown to be well coated with amorphous carbon of approximately $3 \mathrm{~nm}$ in thickness. These results reveal that the SCB particles maintained a loosely connected morphology consisting of $n-S i$ and carbon black particles through bonding by amorphous carbon. This feature of SCB particles is expected to help buffer the volume expansion of $\mathrm{Si}$ nanoparticles during lithiation and delithiation. 


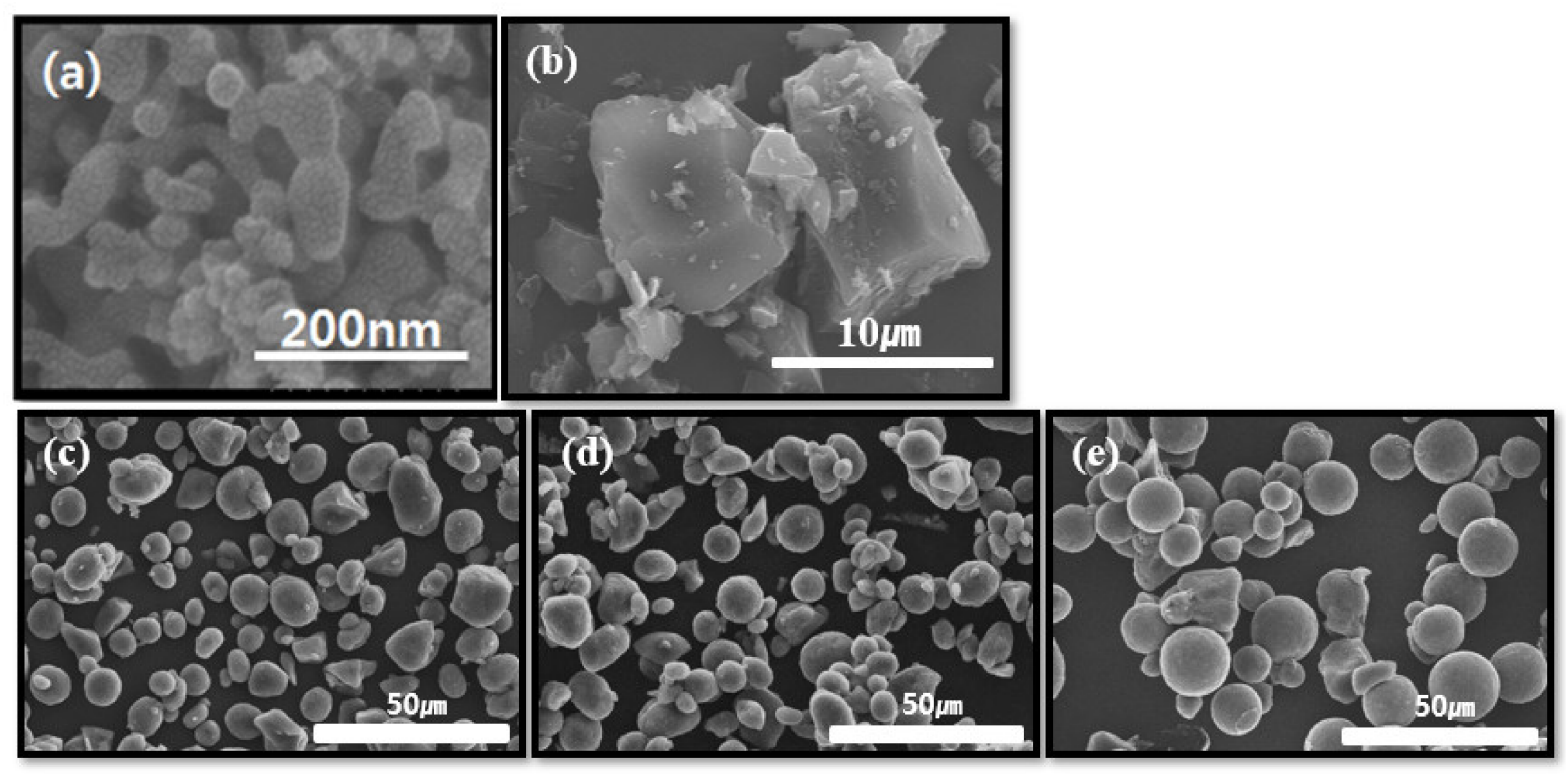

Figure 1. SEM images of (a) nano silicon, (b) hard carbon, (c) HSC, (d) HSBC, and (e) HSBGC.

(a)

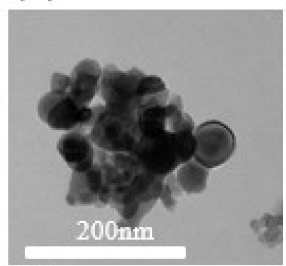

(d) (b)

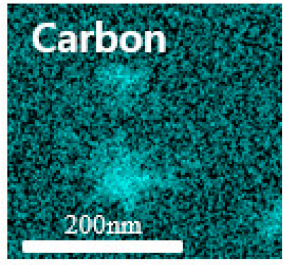

(c)

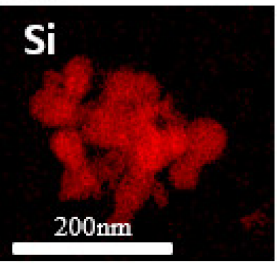

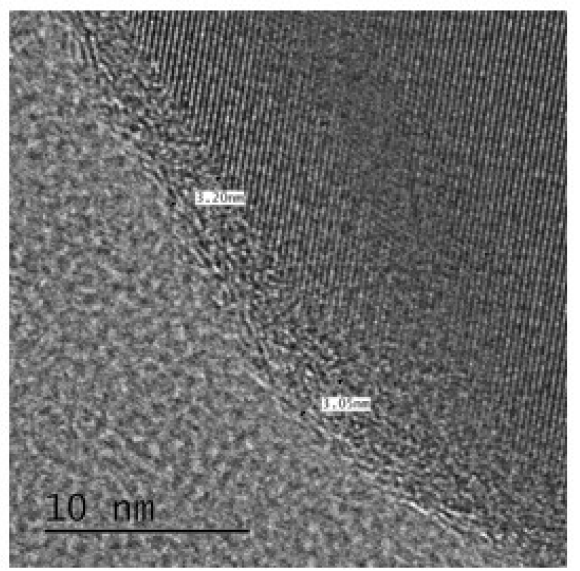

Figure 2. TEM micrographs; (a) image of $\mathrm{SCB},(\mathbf{b}, \mathbf{c})$ corresponding elemental mapping of carbon and silicon, (d) HRTEM image.

Figure 3 shows the particle size distribution of the hard carbon used as a core particle and the core-shell composite samples, HSBC and HSBGC. The distribution shifts from the original core particle to the larger size when a shell layer is added, indicating that the SCB particles adhered to the surface of the core particles with the pitch carbon and the composite, HSBC, is also well encapsulated within a graphite nanosheet shell. 


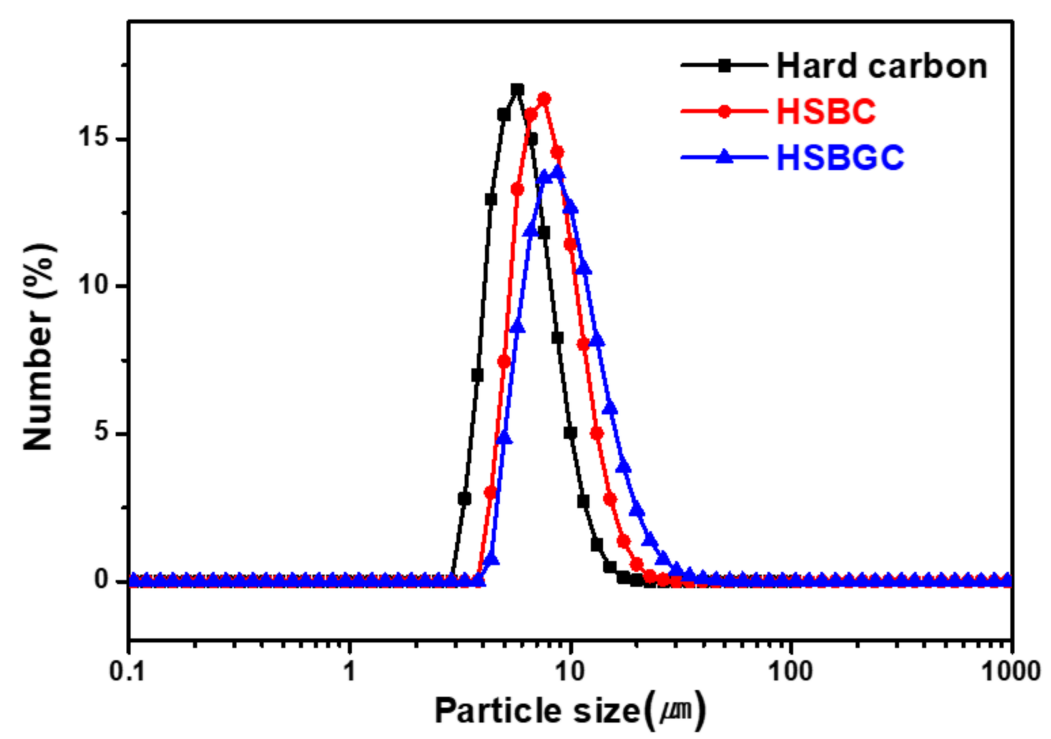

Figure 3. Particle size distribution of hard carbon and core/shell composite HSBC and HSBGC.

The cross-sectional TEM images of the composite HSBGC (in Figure 4) further confirm the dispersion of n-Si particles in the carbon matrix (in the inner shell) and the formation of the outer shell through encapsulation with the graphite nanosheets.
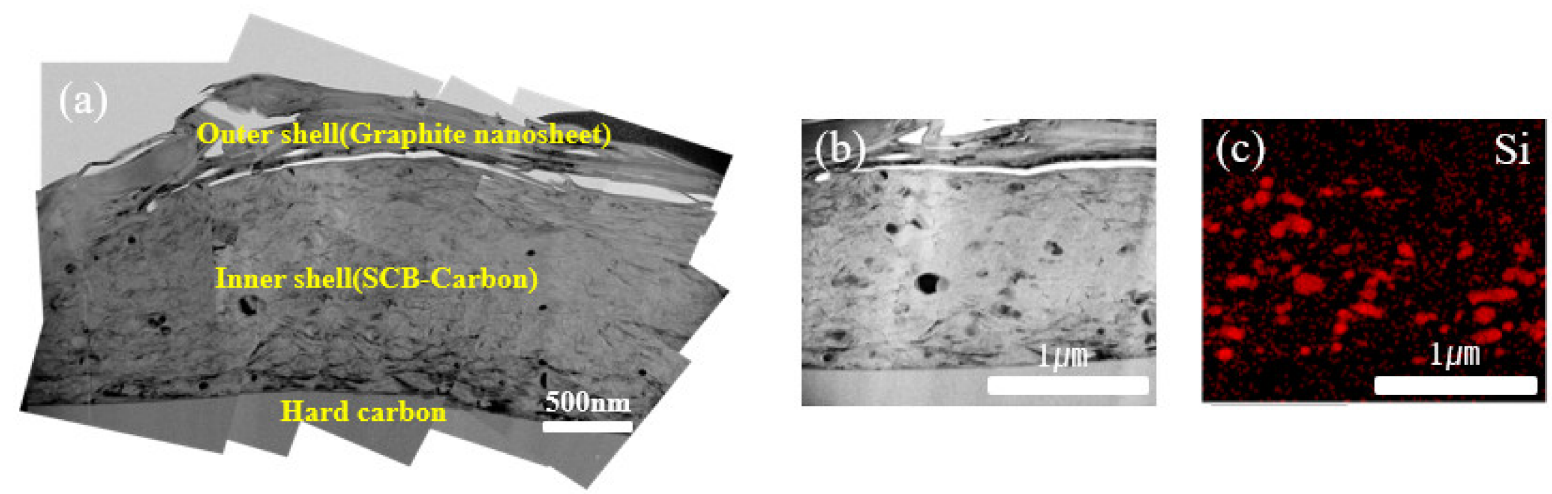

Figure 4. Cross-sectional TEM image of HSBGC sample (a), TEM image of shell region and corresponding elemental mapping of $\mathrm{Si}(\mathbf{b}, \mathbf{c})$.

Figure 5 shows the XRD patterns of hard carbon, SCB, HSBC and HSBGC samples. The XRD pattern of hard carbon shows two broad diffraction peaks, which are attributed to the amorphous carbon [21,22]. The SCB displayed the intense peaks of crystalline $\mathrm{Si}$, in which no diffraction peaks corresponding to carbon black were observed in the XRD pattern, meaning that the carbon black is amorphous. In the case of HSBC, it is seen that the intensity of diffraction in the $2 \theta$ region $20-30^{\circ}$ becomes stronger compared with the peak of the hard carbon, indicating that the pitch carbon in the shell layer has a characteristic of soft carbon with a turbostratic structure [23]. The XRD pattern of HSBGC displays an additional peak at $2 \theta=\sim 27^{\circ}$ due to the coating of graphite nanosheets.

The electrochemical properties of HSC, HSBC and HSBGC electrodes were investigated. Figure 6 shows the charge/discharge curves of the HSC, HSBC and HSBGC samples for the initial two cycles. The initial specific capacities and initial coulombic efficiencies of the samples are given in Table 1. The discharge capacity of the HSBGC sample is lower than that of HSBC as a result of additional coating of some graphite nanosheets on the HSBC sample. The HSBC sample exhibits a higher initial coulombic efficiency compared to HSC. This means that the initial coulombic efficiency of composites is greatly improved by using 
SCB instead of n-Si to form a shell coating layer. It is also noted that the initial coulombic efficiency is slightly improved by the additional coating of some graphite nanosheets on the HSBC sample. The enhancement of the initial coulombic efficiency is attributed to the reduction of the irreversible capacity.

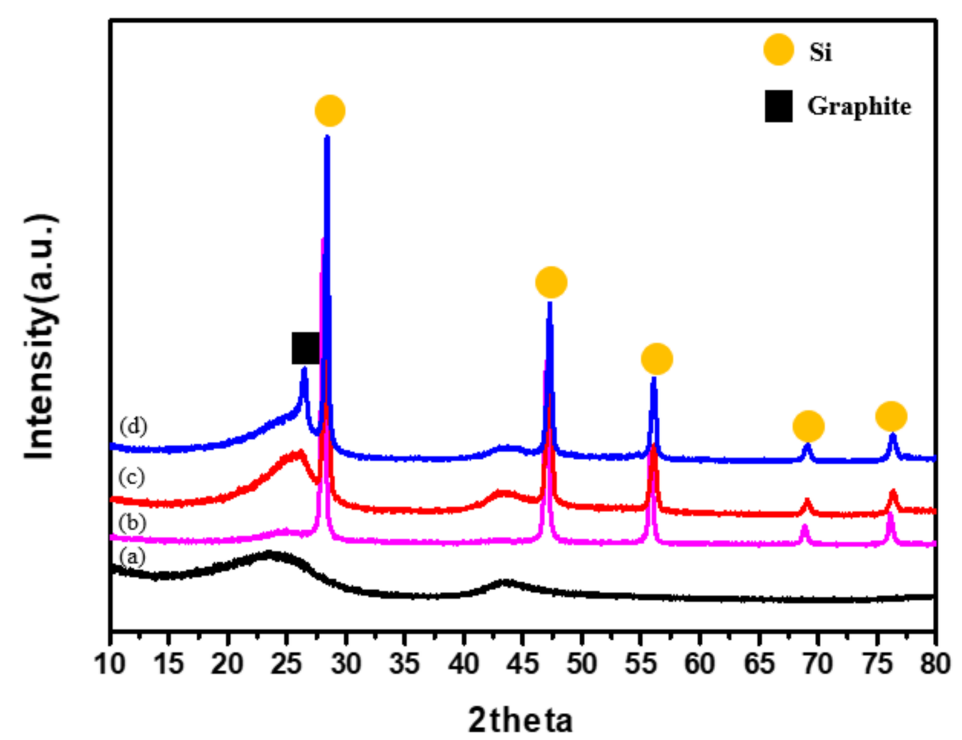

Figure 5. XRD patterns of (a) hard carbon, (b) SCB, (c) HSBC, (d) HSBGC.

(a)

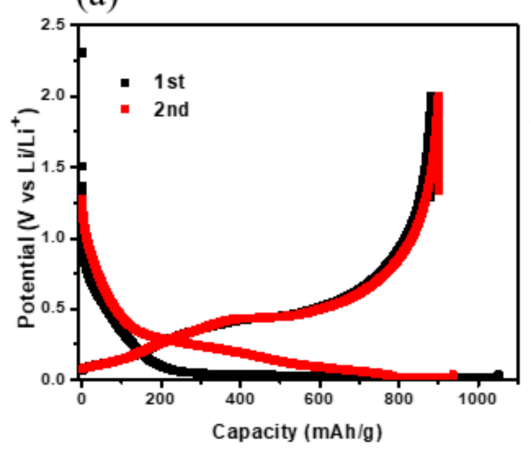

(b)

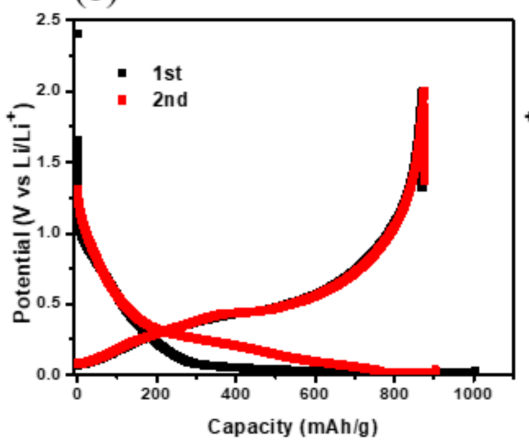

(c)

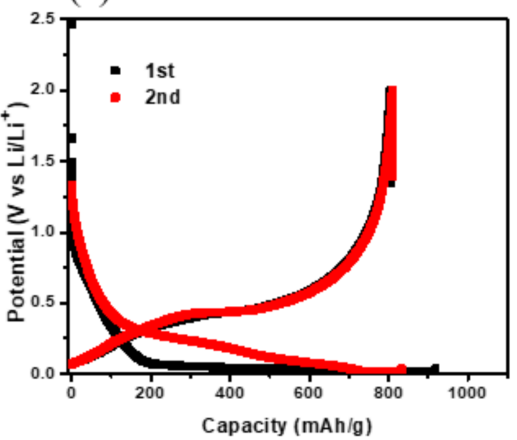

Figure 6. Charge-Discharge curves of (a) HSC, (b) HSBC and (c) HSBGC samples for first two cycles.

Table 1. The reversible capacity, the irreversible capacity and the initial coulombic efficiency of HSC, HSBC and HSBGC samples.

\begin{tabular}{cccc}
\hline Sample Name & ReversibleCapacity $\left(\mathbf{m A g}^{-1}\right)$ & IrreversibleCapacity $(\mathbf{m A g}$ & Initial Coulomb Efficiency (\%) \\
\hline HSC & 881.5 & 170.4 & 83.8 \\
HSBC & 870.4 & 132.3 & 86.8 \\
HSBGC & 804.0 & 114.3 & 87.6 \\
\hline
\end{tabular}

Accordingly, it is considered that the use of SCB and additional coating of the graphite nanosheets would effectively reduce an irreversible reaction with electrolytes, as deduced from the fact that the initial irreversible capacity is largely related with the formation of solid electrolyte interface (SEI) films, which is formed by the decomposition of electrolytes on the surface of electrodes [24-28]. This is consistent with the previous works [17,18,29-31], which found that the approach using few-layer graphene and carbon coating is very effective in improving the electrochemical performance of a Si-based anode, leading to the 
enhancement of the structural stability, electrical conductivity and the protection of $\mathrm{Si}$ from exposing the electrolyte.

The cyclic performances of the HSC, HSBC and HSBGC electrodes are shown in Figure 7. All the electrodes exhibit a fairly good cycling stability, in which the capacity retention ratio after 40 cycles was $87 \%, 92.5 \%$ and $95.2 \%$ for the HSC, HSBC and HSBGC electrodes, respectively. However, it is worth noting that the HSC sample appears to decay slightly after 20 cycles, while HSBC and HSBGC show a highly stable cycle performance, with little capacity decay after 40 cycles.

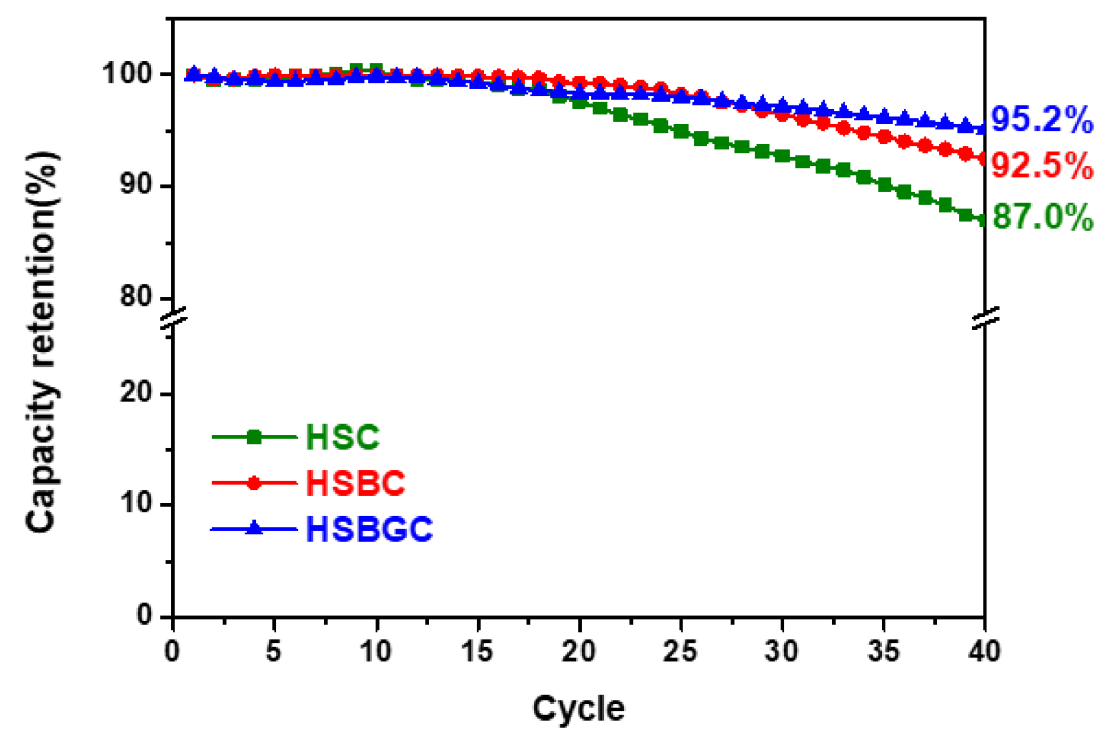

Figure 7. Capacity retention of HSC, HSBC, and HSBGC.

The capacity fading of Si-based electrodes during cycling results from the dramatic volume changes associated with the alloying/dealloying reaction of $\mathrm{Si}$ with $\mathrm{Li}$ could be attributed to the following reasons: (1) the electrical disconnection between electrode components, such as active materials and current collector [20,32] and (2) the continuous formation of SEI film [33-35]. Based on these considerations, the capacity retention of Si-based electrodes during cycling has been expressed in terms of cumulated relative irreversible capacities (RIC) and defined as the ratio between the irreversible capacity loss and the delivered charge capacity [36].

Figure $8 \mathrm{a}, \mathrm{b}$ show the cumulated loss of RIC(DISC) and RIC(SEI) for HSC, HSBC and HSBGC electrodes as a function of cycle, respectively. The irreversibility related to both the electrical contact loss and SEI formation is significantly lower for HSBC and HSBGC electrodes than that for the HSC. The HSBC and HSBGC demonstrate a comparable irreversibility, although the irreversible capacity loss related with electrical disconnection is a slightly larger in the HSBC electrodes than in the HSBGC electrodes (Figure 8a). It is noteworthy that the HSBC and HSBGC electrodes show similar behavior with respect to the irreversibility of SEI formation, as illustrated in Figure 8b, indicating that the introduction of SCB may be effective for a side reaction between Si and an electrolyte. It might, therefore, appear that the superior capacity retention during the cycling of the HSBC and HSBGC electrodes is mainly because an irreversible capacity loss resulting from electrical disconnection and SEI formation is suppressed by using SCB in place of n-Si for the shell coating of composites. The beneficial effects of SCB are as follows: In SCB, n-Si particles are coated with amorphous carbon and bound with carbon black particles, as shown in Figure 2, which can effectively buffer the volume change of Si particles and improve the electronic and ionic conductivity, and facilitate the formation of stable SEI on the surface of n-Si. Moreover, it seems that the additional wrapping with graphite nanosheets can accommodate the significant volume changes of Si during cycling, as deduced from the reduction in the level of irreversibility caused by electrical disconnection (Figure 8a). 
(a)

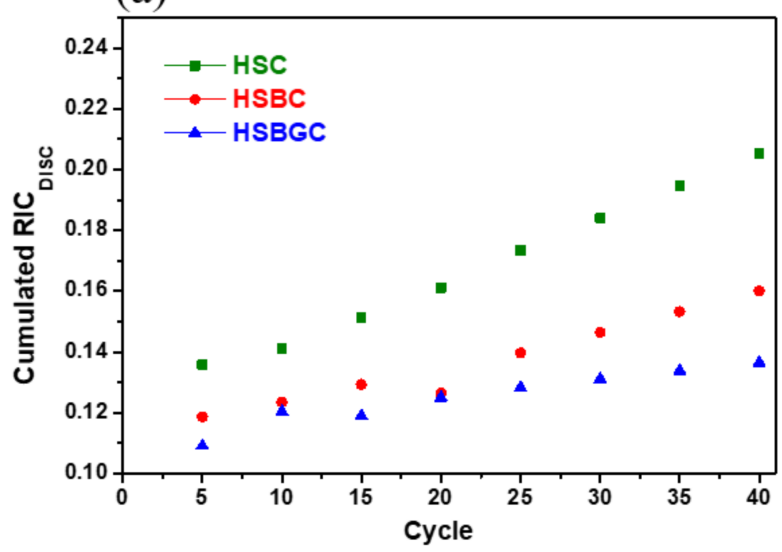

(b)

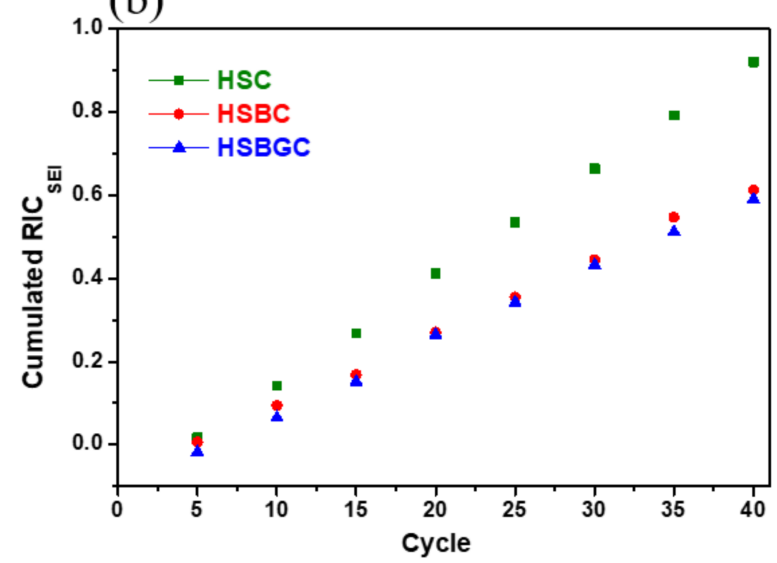

Figure 8. Cumulated relative irreversible capacities related to (a) electrical disconnection and (b) SEI for HSC, HSBC and HSBGC electrodes.

To better understand the capacity fading behavior of these electrodes, EIS measurements were performed on the fully charged electrodes. Nyquist plots for the HSC, HSBC and HSBGC samples, obtained after the 2nd, 10th and 20th cycles, are shown in Figure 9. The spectra consist of a depressed semicircle in the high frequency region and an oblique straight line in the low frequency region. The diameter of the semicircle indicates the charge-transfer resistance and might contain the SEI film resistance and inter-particle contact resistance [37,38]. As illustrated in Figure 9, the diameter of the semicircle in the HSC sample significantly increased after 20 cycles, whereas the diameter of the semicircle slowly increased in the HSBC sample. The HSBGC sample in particular exhibits a highly stable electrochemical reaction resistance up to 20 cycles. This is consistent with the observation in Figure 8, concerning the irreversibility for HSC, HSBC and HSBGC electrodes as a function of the cycle.
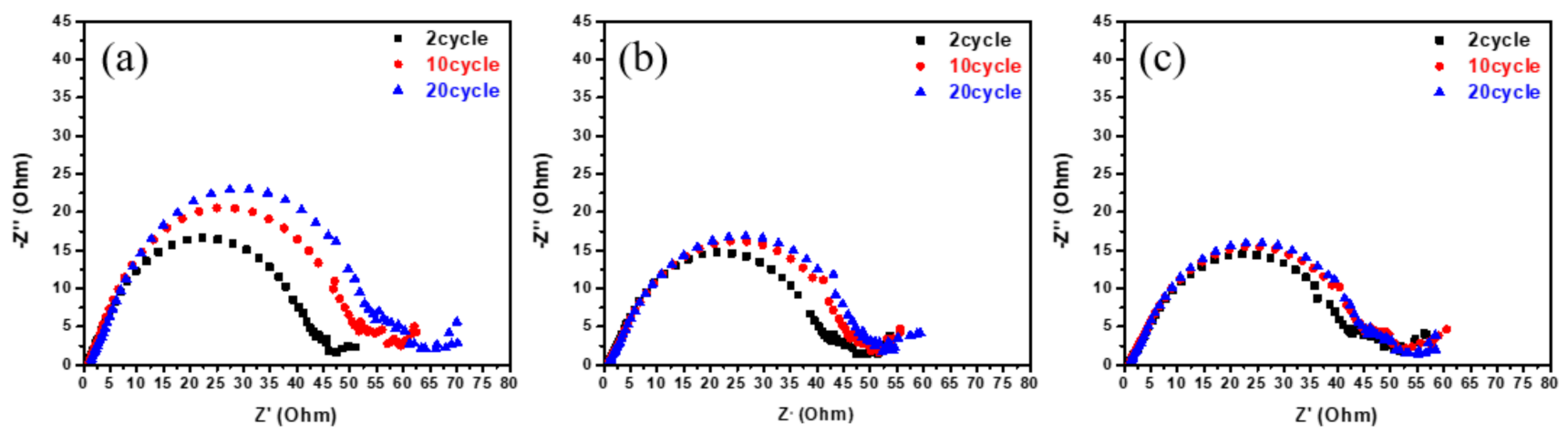

Figure 9. Nyquist plots of (a) HSC, (b) HSBC and (c) HSBGC electrodes.

In addition, the application of SCB and graphite nanosheets for the shell coating of composites leads to the enhanced rate capability of the HSBC and HSBGC samples. The charge (lithiation) rate performance of HSC, HSBC and HSBGC samples is compared in Figure 10. The HSC delivered a poor rate performance compared with the HSBC and HSBGC. Both electrodes of HSBC and HSBGC were found to have a similar charge rate capability, which reveals that the lithiation reaction would not be affected by graphite nanosheet coating if the coating later is thin enough, although the thickness or amount of graphite nanosheets may have a crucial role in the rate performance of the HSBGC samples. 


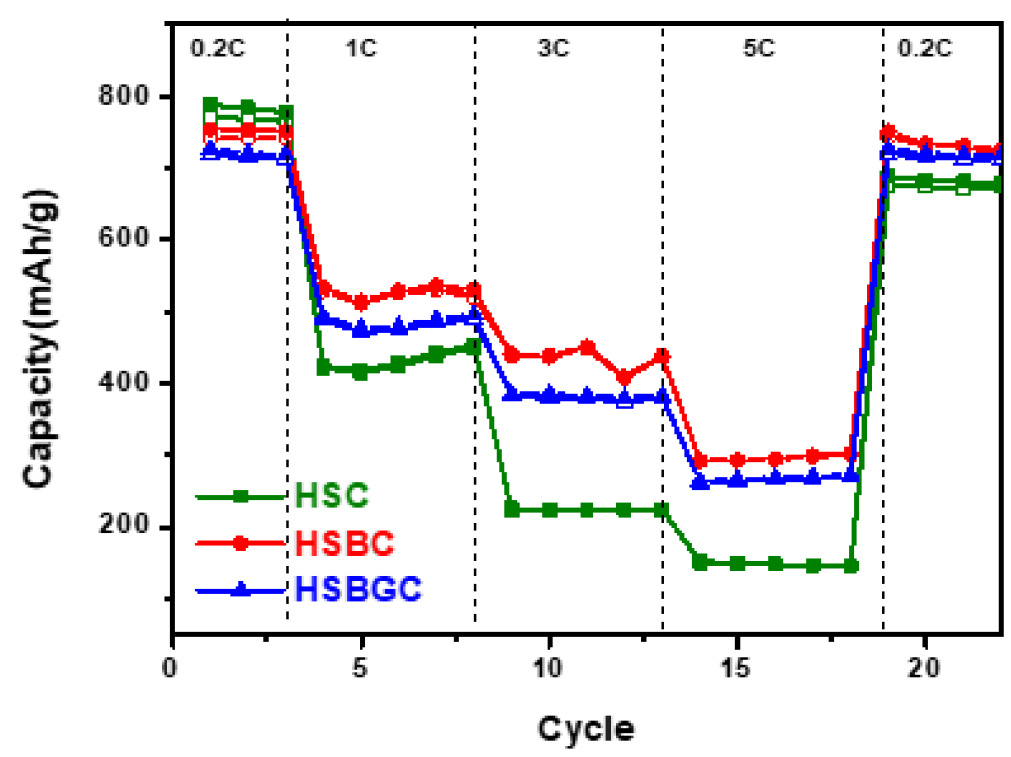

Figure 10. Charge rate performance of HSC, HSBC, and HSBGC electrodes.

The relatively good electrochemical performances of the HSBC and HSBGC samples can be attributed to the well-designed core-shell structure. However, despite the beneficial features, the electrochemical performance still needs to be further improved. The further enhancement in the performance can potentially be achieved via adjusting the following factors: (1) the optimization of parameters, such as the size of the hard carbon particles and graphite nanosheets, the weight ratio between the components comprising composites; (2) the adjustment of the void space surrounding the Si particle through the optimization of the $\mathrm{Si} / \mathrm{CB}$ ratio, the type of $\mathrm{CB}$ and the carbon yield of carbon precursor used for the SCB synthesis. It appears that the void space is very critical for long term cycling stability of $\mathrm{Si} / \mathrm{C}$ composite anode, as demonstrated in many previous works [39-44]. The void space can accommodate the large volume change caused by the lithiation/de-lithiation of $\mathrm{Si}$ and maintain the structural integrity of Si-based anode materials, thereby inhibiting the continuous growth of the SEI film during cycling and (3) the use of electrolyte additives. It is well known that electrolyte additives can significantly enhance the electrochemical performance of Si-based electrodes. Especially, fluorinated ethylene carbonate (FEC) is widely used as an electrolyte additive since it is very affective for forming a passivating SEI film on the Si surface [45-48]. It is known that the passivating SEI layer formed with FEC alleviates the cracking of Si during cycling and suppresses the further formation of SEI film. Considering that the stability of an SEI layer is a prerequisite for an enhanced cycling performance of Si-based anodes, the use of electrolyte additives, such as FEC, would be effective for improving the cycling stability of $\mathrm{Si} / \mathrm{C}$ composite anode. In this study, we used an electrolyte solution without any additive to better understand the effect of the type of shell structure on the performance of composites. Therefore, the electrochemical performances of the composites could be improved by using an electrolyte containing a functional additive.

\section{Conclusions}

Novel core-shell structure hard carbon/Si-carbon composites with multiple shell structures were synthesized to be applied as anode materials for LIBs. We investigated the effect of the shell structure on the electrochemical performances of composites by utilizing three types of shell structure: $\mathrm{Si}$-carbon, $\mathrm{Si}$-carbon black-carbon and $\mathrm{Si}$-carbon black-carbon/graphite nanosheet. It appears that the use of SCB in place of n-Si for the shell coating of composites is of significant importance to achieve the enhanced electrochemical performances of core-shell composite samples. Moreover, the electrochemical properties are further improved by the formation of an outer shell through encapsulation with 
graphite nanosheets. In SCB, n-Si particles were coated with amorphous carbon and bound with carbon black particles, which can effectively buffer the volume change of $\mathrm{Si}$ particles and improve the electronic and ionic conductivity, and facilitate the formation of stable SEI on the surface of n-Si. Moreover, it seems that the additional wrapping with graphite nanosheets is helpful for accommodating the significant volume changes of $\mathrm{Si}$ during cycling.

Author Contributions: Investigation, J.-C.K., K.-J.K.; data curation, J.-C.K.; methodology, K.-J.K.; visualization, J.-C.K.; supervision, S.-M.L.; project administration, S.-M.L.; writing-original draft preparation, J.-C.K.; writing-review and editing, S.-M.L.; All authors have read and agreed to the published version of the manuscript.

Funding: This work was supported by the Technology Innovation Program (20011905, Development of lithium secondary battery materials and cell technology enabling extreme fast charge for urban electric vehicles transportation) funded By the Ministry of Trade, Industry and Energy (MOTIE, Korea).

Conflicts of Interest: The authors declare no conflict of interest.

\section{References}

1. Winter, M.; Besenhard, J.O.; Spahr, M.E.; Novak, P. Insertion electrode materials for rechargeable lithium batteries. Adv. Mater. 1998, 10, 725-763. [CrossRef]

2. Su, X.; Wu, Q.; Li, J.; Xiao, X.; Lott, A.; Lu, W.; Sheldon, B.W.; Wu, J. Silcon-based nanomaterials for lithium-ion batteries. A review. Adv. Energy Mater. 2013, 4, 375-379.

3. Liu, L.; Lyu, J.; Li, T.; Zhao, T. Well-constructed Silicon-based materials as high-performance lithium-ion battery anodes. Nanoscale 2016, 8, 701-722. [CrossRef] [PubMed]

4. Du, F.H.; Wang, K.X.; Chen, J.S. Strategies to succeed in improving the lithium-ion storage properties of silicon nanomaterials. J. Mater. Chem. A 2016, 4, 32-50. [CrossRef]

5. Jin, Y.; Zhu, B.; Lu, Z.; Liu, N.; Zhu, J. Challenges and Recent Progress in the Development of Si Anodes for Lithium-ion Battery. Adv. Energy Mater. 2017, 7, 1700715-1700732. [CrossRef]

6. Liu, X.; Zhu, X.; Pan, D. Solution for the problems of silicon-carbon anode materials for lithium-ion batteries. R. Soc. Open Sci. 2018, 5, 172370-172391. [CrossRef]

7. Chen, X.; Li, H.; Yan, Z.; Cheng, F.; Chen, J. Structure design and mechanism analysis of silicon anode for lithium-ion batteries. Sci. China Mater. 2019, 62, 1515-1536. [CrossRef]

8. Dou, F.; Shi, L.; Chen, G.; Zhang, D. Silicon/Carbon Composite Anode Materials for Lithium-Ion Batteries. Electrochem. Energy Rev. 2019, 2, 149-198. [CrossRef]

9. Asenbauer, J.; Eisenmann, T.; Kuenzel, M.; Kazzazi, A.; Chen, Z.; Bresser, D. The success of graphite as a lithium-ion anode material-fundamentals, remaining challenges, and recent developments including silicon (oxide) composites. Sustain. Energy Fuels 2020, 4, 5387-5416. [CrossRef]

10. Zhao, X.; Lehto, V.-P. Challenges and prospects of nanosized silicon anodes in lithium-ion batteries. Nanotechnology 2021, 32, 042002. [CrossRef]

11. Escamilla-Pérez, A.M.; Roland, A.; Giraud, S.; Guiraud, C.; Virieux, H.; Demoulin, K.; Oudart, Y.; Louvain, N.; Monconduit, L. Pitch-based carbon/nano-silicon composite, an efficient anode for Li-ion batteries. RSC Adv. 2019, 9, 10546-10553. [CrossRef]

12. Zhou, Y.; Guo, H.; Yang, Y.; Wang, Z.; Li, X.; Zhou, R.; Peng, W. Facile synthesis of silicon/carbon nanospheres composite andde materials for lithium-ion batteries. Mater. Lett. 2016, 168, 138-142. [CrossRef]

13. Bahr, J.L.; Mickelson, E.T.; Bronikowski, M.J.; Smalley, R.E.; Tour, J.M. Dissolution of small diameter single-wall carbon nanotubes in organic solvents. Chem. Commun. 2001, 193-194. [CrossRef]

14. Hudson, J. Water-Soluble, Exfoliated, Nonroping Single-Wall Carbon Nanotubes. J. Am. Chem. Soc. 2004, 126, 11158-11159. [CrossRef]

15. Kim, D.-Y.; Kim, H.-V.; Kang, J. In Situ Synthesis of Silicon-Carbon Composites and Application as Lithium-Ion Battery Anode Materials. Materials 2019, 12, 2871. [CrossRef]

16. An, W.; Xiang, B.; Fu, J.; Mei, S.; Guo, S.; Huo, K.; Zhang, X.; Gao, B.; Chu, P.K. Three-Dimensional Carbon-Coating Silicon Nanoparticles Welded on Carbon Nanotubes Composites for High-Stability Lithium-Ion Battery Anodes. Appl. Surf. Sci. 2019, 479, 896-902. [CrossRef]

17. Huang, H.; Rao, P.; Choi, W.M. Carbon-coated silicon/crumpled graphene composite as anode material for lithium-ion batteries. Curr. Appl. Phys. 2019, 19, 1349-1354. [CrossRef]

18. Wang, M.-S.; Wang, G.-L.; Wang, S.; Zhang, J.; Wang, J.; Zhong, W.; Tang, F.; Yang, Z.-L.; Zheng, J.; Li, X. In situ catalytic growth 3D multi-layers graphene sheets coated nano-silicon anode for high performance lithium-ion batteries. Chem. Eng. J. 2019, 356, 895-903. 
19. Li, X.; Yan, P.; Woo, J.H.; Wang, C.; Liu, J.; Zhang, J.-G. Design of porous Si/C-graphite electrodes with long cycle stability and controlled swelling. Energy Environ. Sci. 2017, 10, 1427-1434. [CrossRef]

20. Schott, T.; Robert, R.; Ulmann, P.A.; Lanz, P.; Zürcher Spahr, M.E.; Novak, P.; Trabesinger, S. Cycling Behavior of Silicon-Containing Graphite Electrodes, Part A: Effect of the Lithiation Protocol. J. Phys. Chem. C 2017, 121, 18423-18429.

21. Azuma, H.; Imoto, H.; Yamada, S.; Sekai, K. Advanced carbon anode materials for lithium ion cells. J. Power Sources 1999, 81-82, 1-7. [CrossRef]

22. Ohzawa, Y.; Yamanaka, Y.; Naga, K.; Nakajima, T. Pyrocarbon-coating on powdery hard-carbon using chemical vapor infiltration and its electrochemical characteristics. J. Power Sources 2005, 146, 125-128. [CrossRef]

23. Hishiyama, Y.; Nakamura, M. X-ray diffraction in oriented carbon films with turbostratic structure. Carbon 1995, 10, 1399-1403. [CrossRef]

24. Abe, T.; Takeda, K.; Fukutsuka, T.; Iriyama, Y.; Inaba, M.; Ogumi, Z. Synthesis of highly graphitized carbonaceous thin films by plasma assisted chemical vapor deposition and their electrochemical properties in propylene carbonate solution. Electrochem. Commun. 2002, 4, 310-313. [CrossRef]

25. Li, W.; Chen, M.; Wang, C. Spherical hard carbon prepared from potato starch using as anode material for Li-ion batteries. Mater. Lett. 2011, 65, 3368-3370. [CrossRef]

26. Aurbach, D.; Levi, M.D.; Levi, E.; Schechter, A. Failure and Stabilization Mechanisms of Graphite Electrodes. J. Phys. Chem. B 1997, 101, 2195-2206. [CrossRef]

27. Fong, R.; Sacken, U.V.; Dahn, J.R. Studies of Lithium Intercalation into Carbons Using Nonaqueous Electrochemical Cell. J. Electrochem. Soc. 1990, 137, 2009-2013. [CrossRef]

28. Novák, P.; Ufheil, J.; Buqa, H.; Krumeich, F.; Spahr, M.E.; Goers, D.; Wilhelm, H.; Dentzer, J.; Gadiou, R.; Vix-Guterl, C. The importance of the active surface area of graphite materials in the first lithium intercalation. J. Power Sources 2007, 174, 1082-1085. [CrossRef]

29. Qin, J.; Wu, M.; Feng, T.; Chen, C.; Tu, C.; Li, X.; Duan, C.; Xia, D.; Wang, D. High rate capability and long cycling life of graphene-coated silicon composite anodes for lithium ion batteries. Electrochim. Acta 2017, 256, 259-266. [CrossRef]

30. Chen, H.; Shen, K.; Hou, X.; Zhang, G.; Wang, S.; Chen, F.; Fu, L.; Qin, H.; Xia, Y.; Zhou, G. Si-based anode with hierarchical protective function and hollow ring-like carbon matrix for high performance lithium ion batteries. Appl. Surf. Sci. 2019, 470, 496-506. [CrossRef]

31. Zhang, X.; Wang, D.; Qiu, X.; Ma, Y.; Kong, D.; Müllen, K.; Li, X.; Zhi, L. Stable high-capacity and high-rate silicon-based lithium battery anodes upon two-dimensional covalent encapsulation. Nat. Commun. 2020, 11, 1-9. [CrossRef] [PubMed]

32. Guo, Z.; Zhou, L.; Yao, H. Improving the electrochemical performance of Si-based anode via gradient Si concentration. Mater. Des. 2019, 177, 107851-107857. [CrossRef]

33. Wang, A.; Kadam, S.; Li, H.; Shi, S.; Qi, Y. Review on modeling of the anode solid electrolyte interphase (SEI) for lithium-ion batteries. Comput. Mater. 2018, 15, 1-26. [CrossRef]

34. Cao, C.; Abate, I.I.; Sivonxay, E.; Shyam, B.; Jia, C.; Moritz, B.; Devereaux, T.P.; Persson, K.A.; Steinrück, H.-G.; Toney, M.F. Solid electrolyte interphase on native oxide-terminated Silicon anodes for Li-ion batteries. Joule 2019, 3, 762-781. [CrossRef]

35. Song, W.; Scholties, E.S.; Sherrell, P.C.; Tsang, D.K.H.; Ngiam, J.; Lischner, J.; Fearn, S.; Bemmer, V.; Mattevi, C.; Klein, N.; et al. Electronic structure influences on the formation of the solid electrolyte interphase. Energy Environ. Sci. 2020, 13, 4977-4989. [CrossRef]

36. Gauthier, M.; Mazouzi, D.; Reyter, D.; Lestriez, B.; Moreau, P.; Guyomard, D.; Roue, L. A low-cost and high performance ball-milled Si-based negative electrode for high-energy Li-ion batteries. Energy Environ. Sci. 2013, 6, 2145-2155. [CrossRef]

37. Fan, J.; Fedkiw, P.S. Electrochemical impedance spectra of full cells: Relation to capacity and capacity-rate of rechargeable Li cells using $\mathrm{LiCoO} 2, \mathrm{LiMn} 2 \mathrm{O} 4$, and LiNiO2 cathodes. J. Power Sources 1998, 72, 165-173. [CrossRef]

38. Yang, S.; Feng, X.; Mullen, K. Sandwich-Like, Graphene-Based Titania Nanosheets with High Surface Area for Fast Lithium Storage. Adv. Mater. 2011, 23, 3575-3579. [CrossRef]

39. Li, X.; Meduri, P.; Chen, X.; Qi, W.; Engelhard, M.H.; Xu, W.; Ding, F.; Xiao, J.; Wang, W.; Wang, C.; et al. Hollow core-shell structured porous $\mathrm{Si}-\mathrm{C}$ nanocomposites for Li-ion battery anodes. J. Mater. Chem. 2012, 22, 11014-11017. [CrossRef]

40. Yeom, S.J.; Lee, C.; Kang, S.; Wi, T.-U.; Lee, C.; Chae, S.; Cho, J.; Shin, D.O.; Ryu, J.; Lee, H.-W. Native void space for maximum volumetric capacity in silicon-based anodes. Nano Lett. 2019, 19, 8793-8800. [CrossRef]

41. Ding, X.; Liu, X.; Huang, Y.; Zhang, X.; Zhao, Q.; Xiang, X.; Li, G.; He, P.; Wen, Z.; Li, J.; et al. Enhanced electrochemical performance promoted by monolayer graphene and void space in silicon composite anode materials. Nano Energy 2016, 27, 647-657. [CrossRef]

42. Zhang, F.; Zhu, G.; Wang, K.; Li, M.; Yang, J. Encapsulation of core-satellite silicon in carbon for rational balance of the void space and capacity. Chem. Commun. 2019, 55, 10531-10534. [CrossRef] [PubMed]

43. Ma, J.; Tan, H.; Liu, H.; Chao, Y. Facile and scalable synthesis of Si@void@C embedded in interconnected 3D porous carbon architecture for high performance lithium-ion batteries. Part. Part. Syst. Charact. 2021, 38, 2000288-2000296. [CrossRef]

44. Zhang, H.; Zhang, X.; Jin, H.; Zong, P.; Bai, Y.; Lian, K.; Xu, H.; Ma, F. A robust hierarchical 3D Si/CNTs composite with void and carbon shell as Li-ion battery anodes. Chem. Eng. J. 2019, 360, 974-981. [CrossRef]

45. Huang, W.; Wang, J.; Braun, M.R.; Zhang, Z.; Li, Y.; Boyle, D.T.; Mclntyre, P.C.; Cui, Y. Dynamic structure and chemistry of the silicon solid-electrolyte interphase visualized by cryogenic electron microscopy. Matter 2019, 1, 1232-1245. [CrossRef] 
46. Hou, T.; Yang, G.; Rajput, N.N.; Self, J.; Park, S.-W.; Nanda, J.; Persson, K.A. The influence of FEC on the solvation structure and reduction reaction of $\mathrm{LiPF}_{6} / \mathrm{EC}$ electrolytes and its implication for solid electrolyte interphase formation. Nano Energy 2019, 64, 103881-103893. [CrossRef]

47. Jaumann, T.; Balach, J.; Langklotz, U.; Sauchuk, V.; Fritsch, M.; Michaelis, A.; Teltevskij, V.; Mikhailova, D.; Oswald, S.; Klose, M.; et al. Lifetime vs. rate capability: Understanding the role of FEC and VC in high-energy Li-ion batteries with nano-silicon anodes. Energy Storage Mater. 2017, 6, 26-35. [CrossRef]

48. Li, Q.; Liu, X.; Han, X.; Xiang, Y.; Zhong, G.; Wang, J.; Zheng, B.; Zhou, J.; Yang, Y. Identification of the solid electrolyte interface on Si/C composite anode with FEC as the additive. ACS Appl. Mater. Interfaces 2019, 11, 14066-14075. [CrossRef] 